\title{
In situ sinking-particle flux from collection rates of cylindrical traps
}

\author{
Giselher Gust ${ }^{1, *}$, Hans-Peter Kozerski² \\ ${ }^{1}$ Technical University Hamburg-Harburg, Ocean Engineering1, Lämmersieth 72, 22305 Hamburg, Germany \\ ${ }^{2}$ Institut für Gewässerökologie und Binnenfischerei im Forschungsverbund Berlin e.V., Müggelseedamm 260, \\ 12587 Berlin, Germany
}

\begin{abstract}
The particle accumulation model for cylindrical traps of Gust et al. (1996; Aquat Sci 58:297-326) was verified in 2 limnic field experiments for 70 and $45 \mathrm{~mm}$ diameter traps under inclusion of new plate sediment traps in which the particles settle onto a flat surface under bottom stresses generated by the approaching flow. During 2 measuring campaigns in the River Spree of the total sinking-particle mass, only the 2 fastest-settling groups, representing a mass percentage $<30 \%$, contributed significantly to the material accrued in the cylindrical traps. Of the total accumulation rate of cylinders, the amount obtained by gravitational settling (5 to $10 \%$ ) was very small for the heaviest particle groups and dropped beneath the experimental noise level for slower-sinking groups. Particles settling at speeds $w_{\mathrm{s}}<5 \mathrm{~m} \mathrm{~d}^{-1}$ under approach velocities $>12 \mathrm{~cm} \mathrm{~s}^{-1}$ were hardly retained by the $70 \mathrm{~mm}$ cylinder. The plate sediment trap collected material for which the depositional stress $\tau_{\mathrm{d}}$ of the particles was not exceeded by the bottom stress. Based on the accumulation model and the data, a new and robust trapping protocol was developed which enables the determination of the in situ sinking-particle flux $\left(C_{0} W_{\mathrm{s}}\right)_{i}$ of particle subgroups (running index $i$ ) retained by cylinders. The in situ particle concentrations $C_{0 i}$ are obtained by solving a system of accumulation equations for a set of simultaneously deployed calibrated cylinders of different geometry, while the particle settling speeds $w_{\mathrm{s} i}$ are determined optically in the quiescent settling zone of one of the cylinder traps used. The accumulation equation also provides a method to calibrate cylinder traps on-site. Independent experiments are now needed to give statistical relevance to the new trapping protocol, which operates under the premise that the collected mass is comprised of stable particles (aggregates).
\end{abstract}

KEY WORDS: Sinking-particle flux · Trap protocol · Sediment trap technology · Sample evaluation . Mass accumulation equation · Trap flux under flow

\section{INTRODUCTION}

Sediment traps of various geometries and deployment characteristics form part of the protocol by which the flux of sinking particles is presently determined in major global ocean studies, although unresolved issues on intercalibration and performance prevail. Major obstacles towards a thorough understanding of trap collection rates and their relation to the in situ sinkingparticle flux arise from the interactions between the environmental flow, the trap-internal flow, and the

*E-mail: gust@tu-harburg.de particle entry and retention processes. Initial work in these areas was executed in laboratory and field studies by Gardner (1980), Butman (1986), Hawley (1988), Baker et al. (1988), and many others, who sought to validate the concept of trap similarity. Buesseler (1991) reviewed flux results from radionuclide techniques such as thorium-234 seeding, used to calibrate sinkingparticle collectors (traps) through particle-adhering tracers, from which both undertrapping and overtrapping was inferred. Michaels et al. (1994) concluded from interannual time series in the Sargasso Sea that, in order to explain observed imbalances in the carbon cycle at the North Atlantic Time Series Station BATS at Bermuda, the sinking-particle flux from the eutrophic 
Table 1. Symbols and abbreviations used in this study

\begin{tabular}{|c|c|}
\hline \multicolumn{2}{|c|}{ Latin symbols } \\
\hline A & Full trap aperture \\
\hline$A_{\mathrm{s}}$ & $\begin{array}{l}\text { Active trap aperture through which parti- } \\
\text { cles enter the cylinder }\end{array}$ \\
\hline$C_{\min }, C_{\max }$ & Extremes of $c_{0}$ \\
\hline$c_{0}$ & Mean concentration \\
\hline$C_{0 i}$ & Concentration of ith sinking-particle group \\
\hline$\left(c_{0} W_{\mathrm{s}) i}\right.$ & Sinking-particle flux of ith particle group \\
\hline$i, n$ & $\begin{array}{l}\text { Summation indices (for sinking-particle } \\
\text { subgroups }[i] \text {, traps and experiment no. }[n] \text { ) }\end{array}$ \\
\hline$m^{2}$ & Square meter \\
\hline$M_{\mathrm{TP}}$ & Flat-plate mass collection rate \\
\hline$M_{\text {Tmeas }}$ & Total mass collected by trap \\
\hline$M_{\text {Tcalc }}$ & $\begin{array}{l}\text { Total mass calculated to accrue in a cylinder } \\
\text { trap based on Eq. (1) }\end{array}$ \\
\hline$M_{\text {Tgravi }}$ & $\begin{array}{l}\text { Mass accrued in cylinder trap by gravita- } \\
\text { tional entry process per particle subgroup } i\end{array}$ \\
\hline$M_{\mathrm{T} i}$ & $\begin{array}{l}\text { Mass of sinking-particle subgroup } i \text {, via } \\
\text { Eq. (1) or from settling chamber method }\end{array}$ \\
\hline$Q$ & Flushing rate \\
\hline$r$ & Radial position \\
\hline$R_{i}$ & $\begin{array}{l}\text { Trapping ratio }\left(R_{i}=C_{\mathrm{o} i} Q / C_{\mathrm{o} i} A_{\mathrm{s}} W_{\mathrm{s} i}\right) \text { per parti- } \\
\text { cle subgroup } i\end{array}$ \\
\hline$t$ & Time \\
\hline$t_{0}$ & Start time \\
\hline$u_{*}$ & Local friction velocity $\left[u_{*}=(\tau / \rho)^{1 / 2}\right]$ \\
\hline$u_{\mathrm{D}}$ & $\begin{array}{l}\text { Speed inside trap, } 1.5 \mathrm{~cm} \text { beneath baffle at } \\
\text { downstream side }\end{array}$ \\
\hline$u_{* \mathrm{~d}}$ & Deposition-threshold friction velocity \\
\hline$u_{\mathrm{f}}$ & Approach velocity \\
\hline$<u *>$ & Spatially averaged friction velocity \\
\hline$W_{\mathrm{si}}$ & $\begin{array}{l}\text { Particle settling speed per particle subgroup } \\
i\end{array}$ \\
\hline y & Yield function \\
\hline \multicolumn{2}{|c|}{ Greek symbols } \\
\hline$\tau$ & Bottom stress \\
\hline$\tau_{\text {crit }}$ & Critical erosion stress of bed particles \\
\hline$\tau_{\mathrm{d}}$ & $\begin{array}{l}\text { Depositional threshold stress of settling par- } \\
\text { ticles }\end{array}$ \\
\hline$\vartheta$ & Temperature \\
\hline
\end{tabular}

zone may miss $80 \%$ of the sinking particles. At the same time, Gust et al. (1992, 1994, 1996) studied hydrodynamic effects on the particle collection behavior of cylindrical tubes of $70 \mathrm{~mm}$ inner diameter (i.d.) and of cones, both in situ and in the laboratory. They observed in cylinders for monosized particle distributions overcollection, undercollection and same-rate collection of particles in comparison to Stokes settling curves (which represent the rain gauge equation). In synthesis, a semi-empirical model emerged for the mass accumulation rates in cylinders, revealing the significance of the strength of the approaching flow and a reduced trap aperture area for particle entry. With this starting point, equations were proposed to calculate a posteriori the in situ flux of the fastest-sinking particle group from the trap-collected mass.

An independent means for obtaining sinking-particle fluxes became available with the development of a plate sediment trap for moving waters (Kozerski \& Leuschner in press). Here the sinking particles settle through a surface boundary layer which is generated by the approaching flow. Trap-internal recirculation cells, characteristic of funnels and cylinders, are absent. The sedimentation rate of this trap can be related to the sinking particle flux at low approach velocities $\left(u_{\mathrm{f}}<25 \mathrm{~cm} \mathrm{~s}^{-1}\right)$ once the local bottom stress of the collection surface and the particle deposition thresholds are known.

In this paper, data from field intercomparisons of particle collection rates of cylindrical and plate traps are presented for a natural mixed population of sinking particles. The results are used in order to verify the cylindrical-trap accumulation model proposed by Gust et al. (1996). This exercise reveals device-related particle winnowing under flow which can prevent the collection of the full sinking-particle spectrum. The reassessment of the flux correction equation leads to the development of a new trapping protocol for moored and tethered cylinders by which realistic estimates of the in situ flux of trap-retained particle subgroups can be obtained.

\section{MATERIALS AND METHODS}

Mass collection equations and flux corrections. The effects of hydrodynamics on the mass accumulation rates of the cylindrical trap with $70 \mathrm{~mm}$ i.d. and an aspect ratio of 8.6 were evaluated by Gust et al. (1996) for 3 discrete, narrow-sized quartz particle groups with mean sinking velocities of $173,54,13 \mathrm{~m} \mathrm{~d}^{-1}$, respectively. Based on the flow-related trap variables 'flushing rate $Q\left(u_{\mathrm{f}}\right)^{\prime}$, ' yield function $y\left(w_{\mathrm{si}}, u_{\mathrm{f}}\right)$ ', and 'active trap aperture area $A_{\mathrm{s}}$ ' (which differ with trap geometry), for a cylinder with an adequately large aspect ratio (which depends on the Reynolds number [see Lau 1979]), and the particle variables 'concentration $C_{0 i}$ ', and 'sinking velocity $W_{\mathrm{si}}{ }^{\prime}$, a generalized model framework was derived for the mass collection process of cylindrical traps. The resulting mass accumulation formula is

$$
M_{\mathrm{T}}=\sum M_{\mathrm{T} i}=\sum\left\{y\left(u_{\mathrm{f}}, w_{\mathrm{s}}\right) c_{0} t\left[Q\left(\mathrm{u}_{\mathrm{f}}\right)+A_{\mathrm{s}} W_{\mathrm{s}}\right]\right\}_{i}
$$

where all symbols used are explained in Table 1. By rearranging the cylinder accumulation Eq. (1), the in situ flux of particles collected by a cylindrical trap can be obtained from

$$
\left(w_{\mathrm{s}} c_{0}\right)=\sum\left(w_{\mathrm{si}} C_{0 i}\right)=\sum\left\{M_{\mathrm{Ti}} /\left[y\left(u_{\mathrm{f}}\right)_{i} A_{\mathrm{s}} t\right]-Q\left(u_{\mathrm{f}}\right) C_{0 i} / A_{\mathrm{s}}\right\}(2)
$$


Table 2. Specifics of traps used. Material of mechanical parts is Perspex

\begin{tabular}{|lll|}
\hline Trap & Specifics & Source \\
\hline Type 1 (C45) & Cylinder, $45 \mathrm{~mm}$ i.d., $52 \mathrm{~mm}$ o.d., length $360 \mathrm{~mm}$, no baffles & Kozerski (1994) \\
Type 2 (C70) & Cylinder, $70 \mathrm{~mm}$ i.d., $75 \mathrm{~mm}$ o.d., length $600 \mathrm{~mm}$, with baffles & Knauer et al. (1979) \\
Type 3 (PT) & Flat circular plate, $148 \mathrm{~mm}$ diameter with bevel & Kozerski \& Leuschner (inpress) \\
Type 4 (MC) & Chamber trap, 195 mm i.d., $100 \mathrm{~mm}$ height, with fluid exchange, prototype & Gust \& Mueller (1997) \\
\hline
\end{tabular}

Application of Eq. (2) critically depends on the error margins of the measured trap-specific and environmental variables. Note that Eq. (2) leads to the classical trap flux equation

$$
\left(w_{\mathrm{s}} C_{0}\right)=M_{\mathrm{T}} / A t
$$

for the case of negligible slip velocity at trap aperture, since then $Q\left(u_{\mathrm{f}}\right) \rightarrow 0$ and $A_{\mathrm{s}} \rightarrow A$.

For a plate trap, the collection process of mass can be connected with the in situ particle flux through a relationship between the particle parameters $w_{\mathrm{s}}$ (settling velocity), $\tau_{\mathrm{d}}$ (depositional threshold stress), $\tau_{\text {crit }}$ (critical erosion stress) and the bottom stress $\tau$ active at the collection site. In the literature (Westrich 1988), the flatplate mass collection rate $M_{\mathrm{TP}}$ (per experiment duration and collection area) is given as

$$
M_{\mathrm{TP}}=\sum M_{\mathrm{TP} i}=\sum\left[c_{0} W_{\mathrm{s}}\left(1-\tau / \tau_{\mathrm{d}}\right)\right]_{i} \quad \text { for } \tau<\tau_{\mathrm{d}}
$$

In contrast to a trap with cavity flow, where the collected material can only be resuspended if an insufficient aspect ratio permits the internal flow cell to reach the deposited mass, for a plate sediment trap the collected material is permanently exposed to the boundary-layer stress. It is resuspended for $\tau>\tau_{\text {crit. }}$. Furthermore, the plate sediment trap only collects those sinking particles for which the acting bottom stress $\tau<$ $\tau_{\mathrm{d}}$. Therefore with an increasing flow strength, only increasingly heavier particles can be deposited. The particle deposition stress $\tau_{\mathrm{d}}$ thus determines the flow speed beyond which no particles of a selected in situ subgroup can sediment on the plate surface.

Sediment traps. One type of trap was the MultiPIT, a hollow cylinder with baffles, an aperture diameter of $70 \mathrm{~mm}$, a length of $600 \mathrm{~mm}$, and an aspect ratio of 8.6. This cylinder version has been in extensive use at the time series stations within the Joint Global Ocean Flux Study. The second type of trap was a cylinder without baffles of $45 \mathrm{~mm}$ diameter and a length of $360 \mathrm{~mm}$, yielding an aspect ratio of 8 . The sinking particles are carried into the cylinder interiors at the downstream portion $A_{\mathrm{s}}$ of the full trap aperture $A$ by both gravitational settling and advective movement, the latter due to the flow-generated trap-internal recirculation cell (Fig. 1 of Gust et al. 1996). From the bottom of this cir- culation cell, fractions of the sinking-particle subgroups enter into the underlying quiescent collection zone [expressed by the yield function $\left.y\left(w_{\mathrm{s}}, u_{\mathrm{f}}\right)\right]$.

The third and fourth types were plate sediment traps. Here, the particles sink from the water column through a plate boundary layer onto a flat surface. The bottom stress is generated either by the approaching flow (type 3) or by a rotating disk plus central fluid removal inside a chamber with external fluid exchange (type 4). The design specifications and literature sources are given in Table 2. The plate sediment trap (type 3) was developed and extensively tested by Kozerski \& Leuschner (2000). The microcosm (plate trap type 4) is a modification of a hydrodynamically calibrated erosion and respiration chamber with spatially homogeneous bottom stress (Gust 1987, Gust \& Mueller 1997). Here the chamber fluid is constantly exchanged with the outside, ensuring environmental particle concentrations $C_{0}$ inside the chamber.

Exposure of traps and supporting measurements. Two field experiments were devised to compare collection rates of a multi-component sinking-particle pool for trap types with different hydrodynamic behavior. Single or multiple traps of 4 designs were simultaneously exposed to the same prevailing flow in a side arm of the River Spree (Site 1, Fig. 1) during 5 field intercomparison runs from May 27 to 29, 1998. Run time lasted either 150 or $840 \mathrm{~min}$. All model-relevant environmental, flow, and particle parameters were recorded for this site (Table 3). A total of 5 traps and 5 skin friction sensors for flow and bottom stress measurements (Gust 1988) were deployed $30 \mathrm{~cm}$ beneath the surface (2 plate sediment traps of type 3, 1 microcosm (plate type 4), one $70 \mathrm{~mm}$ cylinder, one $45 \mathrm{~mm}$ cylinder, and a plate trap dummy for surface stress measurements. The traps were positioned in 2 clusters $3 \mathrm{~m}$ laterally apart with negligible mutual interference (see Fig. 1). Of the total of 5 experimental runs executed, 2 provided collection rates at an approach velocity $u_{\mathrm{f}} \approx 6 \mathrm{~cm} \mathrm{~s}^{-1}$, close to one of the speeds where the accumulation rates of the $70 \mathrm{~mm}$ cylinder trap had been calibrated by Gust et al. (1996). The speed of the river flow was set for each experiment by a weir but was affected by wind conditions as well. 


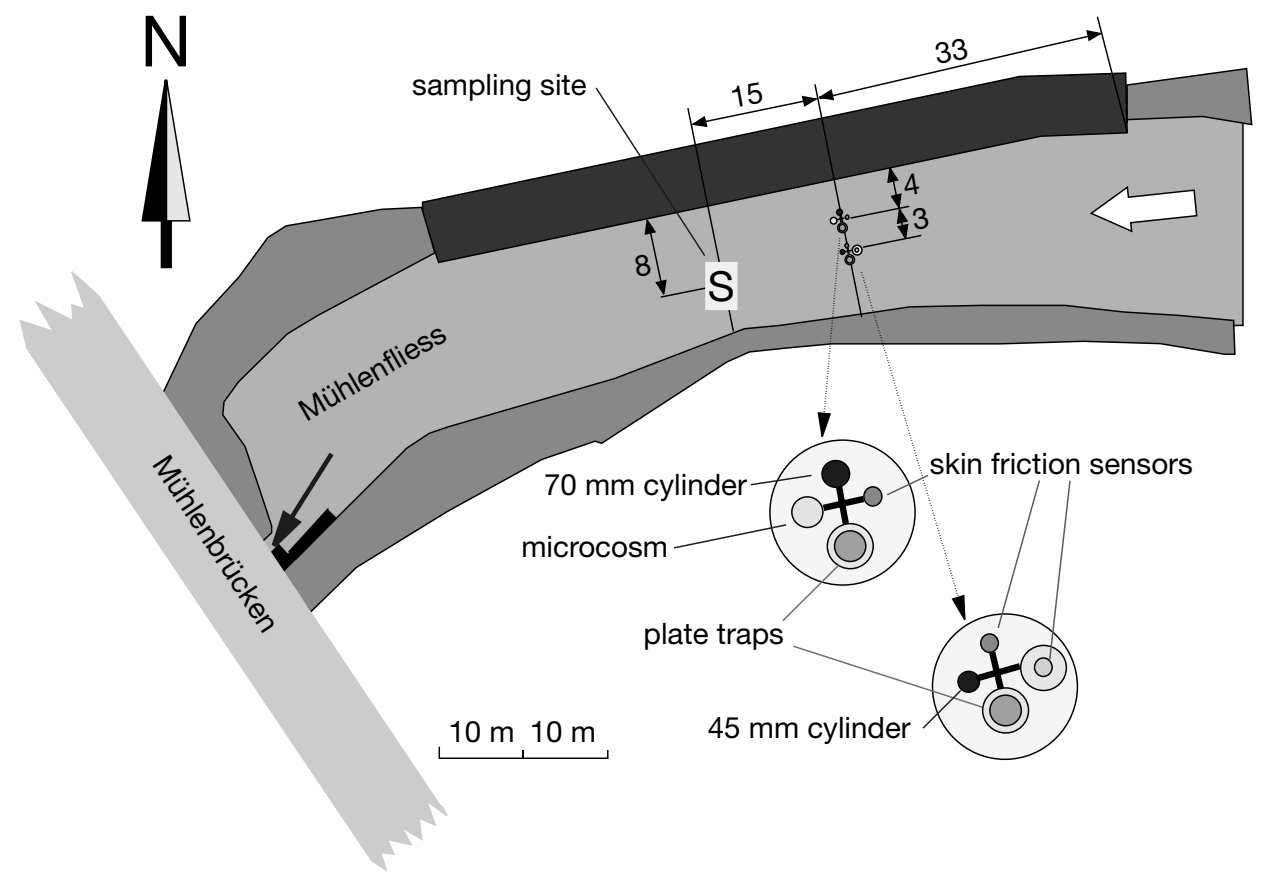

Fig. 1. Experimental Site 1 on the River Spree in Fürstenwalde, Geremany, with the arrangement of the collection devices, shown enlarged. The skin friction sensors, facing the approaching flow, are used to measure $u_{\mathrm{f}}$. All lengths are given in $\mathrm{m}$

Time series of approaching flow speed $u_{\mathrm{f}}$ at each trap cluster, trap-internal speed $u_{\mathrm{D}}$ in the $70 \mathrm{~mm}$ cylinder trap (at $1.5 \mathrm{~cm}$ beneath the baffles) on the downstream side, and friction velocity $\left\langle u_{*}>\right.$ averaged over the collection areas of the 2 types of plate traps were obtained from both short-term averaged measurements by a rotor-type current meter (accuracy ca 15\%) and time series measurements at $20 \mathrm{~Hz}$ by temperature-compensated hot film anemometry with signals stored digitally as 12-bit words (accuracy $5 \%$ ).

The local friction velocity $u_{*}\left[=(\tau / \rho)^{1 / 2}\right]$ of the plate sediment trap was measured at 2 radial locations (at 40

Table 3. Experiments executed and parameters measured at Site 1 (River Spree, location: Mühlenfliess in Fürstenwalde) and Site 2 (River Spree, location 'Werder'). Trap abbreviations for arrays 1 and 2 represent cylinder traps with 45 and 70 mm i.d. (C45, C70), plate sediment trap type 3 (PT), plate dummy for bottom stress data (PTD), plate sediment trap type 4 (MC)

\begin{tabular}{|c|c|c|c|c|c|c|c|c|c|c|c|c|c|}
\hline \multirow{3}{*}{\multicolumn{2}{|c|}{$\begin{array}{l}\text { Site } \mathbf{1 , 1 9 9 8} \\
\text { Run Date } \\
\text { no. }\end{array}$}} & \multirow{3}{*}{$\begin{array}{l}\text { Time } \\
\text { (h) }\end{array}$} & \multirow{3}{*}{$\begin{array}{l}\text { Duration } \\
\text { (min) }\end{array}$} & \multirow{2}{*}{\multicolumn{3}{|c|}{ Sampling array 1}} & \multirow{2}{*}{\multicolumn{3}{|c|}{ Sampling array 2}} & \multirow{2}{*}{\multicolumn{2}{|c|}{ Settling chamber }} & \multicolumn{2}{|c|}{ Environment } \\
\hline & & & & & & & & & & & & Temp. & Velocities \\
\hline & & & & $\mathrm{C} 70$ & $\mathrm{MC}$ & PT & $\mathrm{C} 45$ & PTD & PT & $\begin{array}{cc}C_{0} & C_{0} \\
\left(\mu \mathrm{gl}^{-1}\right)\end{array}$ & $i \begin{array}{c}W_{\mathrm{s} i} \\
\left(\mathrm{~cm} \mathrm{~s}^{-1}\right)\end{array}$ & $\begin{array}{c}\vartheta \\
\left({ }^{\circ} \mathrm{C}\right)\end{array}$ & $\begin{array}{c}u_{\mathrm{f}}<u_{*}> \\
\left(\mathrm{cm} \mathrm{s}^{-1}\right)\end{array}$ \\
\hline 1 & May 28 & $16: 05-18: 35$ & 150 & $x$ & $x$ & $x$ & $x$ & $x$ & $x$ & & & $x$ & 2.1 \\
\hline 2 & May 28 & $11: 25-13: 55$ & 150 & $x$ & $x$ & $x$ & $x$ & $x$ & $x$ & & & $x$ & 3.2 \\
\hline 3 & May 28 & $19: 30-09: 45$ & 855 & $x$ & $x$ & $x$ & $x$ & $x$ & $x$ & & & & 4.5 \\
\hline 4 & May 27 & $17: 30-20: 00$ & 150 & $x$ & $x$ & $x$ & $x$ & $x$ & $x$ & & & & 6.4 \\
\hline \multirow[t]{2}{*}{5} & May 27-28 & $20: 30-10: 17$ & 827 & $x$ & $\times$ & $\times$ & $\times$ & $x$ & $\times$ & $\times$ & $x$ & & 6.2 \\
\hline & Jul 20 & & & & & & & & & $\times$ & $\times$ & $x$ & \\
\hline \multirow{2}{*}{\multicolumn{2}{|c|}{ Site 2, 1999}} & \multirow{3}{*}{$\begin{array}{l}\text { Time } \\
(\mathrm{h})\end{array}$} & \multirow{3}{*}{$\begin{array}{l}\text { Duration } \\
\text { (min) }\end{array}$} & \multirow{2}{*}{\multicolumn{3}{|c|}{ Trap array 1}} & & & & \multirow{2}{*}{\multicolumn{2}{|c|}{ Settling chamber }} & \multicolumn{2}{|c|}{ Environment } \\
\hline \multirow{2}{*}{\multicolumn{2}{|c|}{$\begin{array}{l}\text { Run } \\
\text { no. }\end{array}$}} & & & & & & & & & & & Temp. & Velocities \\
\hline & & & & $\mathrm{C} 45$ & & $\mathrm{C} 70$ & & & & $\begin{array}{cc}C_{0} & C_{0} \\
\left(\mu \mathrm{g} \mathrm{l}^{-1}\right)\end{array}$ & $W^{i} \quad \begin{array}{c}W_{\mathrm{si}} \\
\left(\mathrm{cm} \mathrm{s}^{-1}\right)\end{array}$ & $\begin{array}{c}\vartheta \\
\left({ }^{\circ} \mathrm{C}\right)\end{array}$ & $\begin{array}{l}u_{\mathrm{f}}<u_{*}> \\
\left(\mathrm{cm} \mathrm{s}^{-1}\right)\end{array}$ \\
\hline 1 & Apr 20 & $12: 20-16: 34$ & 254 & $x$ & & $x$ & & & & $\times$ & $\times$ & $x$ & $\times$ \\
\hline 2 & Apr 20-21 & 20:00-09:18 & 798 & $\times$ & & & & & & $\times$ & & $x$ & $\times$ \\
\hline 3 & Apr 21 & $11: 24-14: 37$ & 197 & $x$ & & & & & & $\times$ & & $x$ & \\
\hline
\end{tabular}




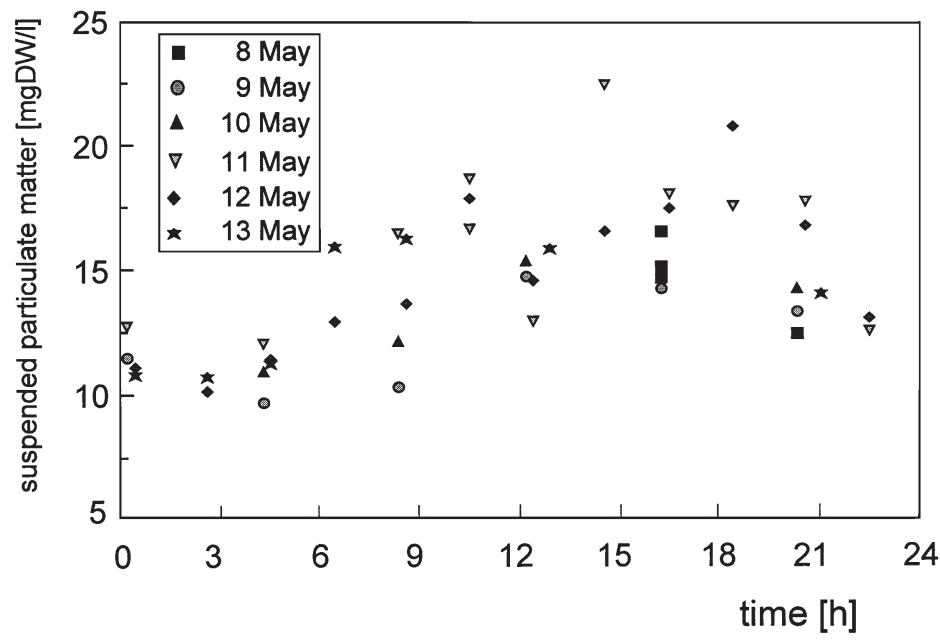

Fig. 2. Diurnal pattern of mean concentration $c_{0}$ of suspended particles for May 8 to 13, 1998, in the Mühlenfliess at Fürstenwalde

and $85 \mathrm{~mm}$ off center) of the dummy version of trap type 3 with $148 \mathrm{~mm}$ radius, and at the radial position $(\mathrm{r}=85 \mathrm{~mm})$ inside a microcosm of $200 \mathrm{~mm}$ diameter. The calibration curves of the hot-film sensors measuring flow speeds and local friction velocities $u_{*}$ were confirmed by later calibrations in a laboratory flume by means of laser Doppler anemometry (Junglewitz et al. 1997). The spatially homogeneous friction velocity $<u_{*}>$ was increased for the microcosm with each run in order to determine the particle deposition threshold $\tau_{\mathrm{d}}\left(u_{* \mathrm{~d}}\right)$ (see Eq. 4$)$.

Experimental site and its suspended matter. The River Spree is a regulated lowland river southeast of Berlin (Germany). Its $400 \mathrm{~km}$ long course includes reservoirs, lakes and channelled sections. The measuring site, the river bypass 'Mühlenfliess' in Fürstenwalde (40 km east of Berlin) is $180 \mathrm{~m}$ long. Its width varies between 10 and $20 \mathrm{~m}$, and its depth between 0.3 and $1.8 \mathrm{~m}$ (Fig. 1). A relatively straight upstream reach of more than $50 \mathrm{~m}$ of constant mean depth was chosen. For the experiments, the flow in the river bypass was regulated and provided steady mean velocities in the surface layer (up to $1 \mathrm{~m}$ below the surface) per run in the selected range of 2 to $6 \mathrm{~cm} \mathrm{~s}^{-1}$. In contrast to the bypass, the flow velocity in the river and channels ranged between 20 and $90 \mathrm{~cm} \mathrm{~s}^{-1}$. The suspended particles were mostly of biological origin, autochthonously produced in the river system, which led to the dominance of very slowly sinking particles. The particle concentration fluctuates seasonally and diurnally (Kozerski et al. 1991) as demonstrated in Fig. 2. The dry weight was determined by filtration with preweighed Sartorius cellulose acetate membrane filters $0.45 \mu \mathrm{m}$, diameter $25 \mathrm{~mm}$, dried at $105^{\circ} \mathrm{C}$ for $2 \mathrm{~h}$.
The sinking-particle velocity spectrum of the suspended load was estimated on July 20,1998, utilizing a settling chamber method (SCM) developed by Kozerski (1994). From a cylinder array (4 tubes, settling length $=300 \mathrm{~mm}$, diameter $=45 \mathrm{~mm}$ ) filled with the natural suspension at same start time $t_{0}$, the settled mass was determined after 20,60, 180 and 1440 min of exposure of individual settling tubes. This provided the concentrations $C_{0 i}$ for each of 5 particle subgroups with settling velocities $W_{\mathrm{si}}$ ranging from $<0.3 \mathrm{~m} \mathrm{~d}^{-1}$ (slowest) to $>21.6 \mathrm{~m} \mathrm{~d}^{-1}$ (fastest).

\section{RESULTS}

The on-site measurements at Site 1, executed in May 27-29 and July 20, 1998, provided the input variables to test the trap accumulation model of Gust et al. (1996). While the momentary particle concentration $c_{0}$ was $14.2 \mathrm{mg} \mathrm{l}^{-1}$ on May 27 at 15:45 h, a mean concentration $c_{0}$ of $12.0 \mathrm{mg} \mathrm{l}^{-1}$ was used in the calculations for the day/evening runs, and one of $10.0 \mathrm{mg} \mathrm{l}^{-1}$ for the overnight runs, based on diurnal concentration pattern observed May 8-15, 1998, at this site. Total sinkingparticle concentration on July 20 was $6.2 \mathrm{mg} \mathrm{l}^{-1}$. Most $(\sim 70 \%)$ of the river seston was concentrated on either date in the settling velocity range $w_{\mathrm{si}}<7.2 \mathrm{~m} \mathrm{~d}^{-1}$. The water samples for the particle velocity spectra collected on May 27-28 were contaminated during processing. Consequently, the mass ratios of the particle settling velocity classes from July 20 were also used for the particle concentrations May 27-29 (Fig. 3). During the May 27-29 experiments, the mean daily water temperature increased monotonically from 17.2 to $19^{\circ} \mathrm{C}$ due to solar radiation.

The masses collected per trap and experiment at Site 1 are shown as mg dry weight (mg DW) in Table 4. They are expressed in the lower part of Table 4 as trapping rates based on Eq. (3). The rates ranged from 2 to $14 \mathrm{~g} \mathrm{DW} \mathrm{m}^{-2} \mathrm{~d}^{-1}$ for the boundary layer traps and from 28 to $82 \mathrm{~g} \mathrm{DW} \mathrm{m}^{-2} \mathrm{~d}^{-1}$ for the cylindrical traps. With regard to the hydrodynamic details, the speed of the approaching flow did not exceed $6.4 \mathrm{~cm} \mathrm{~s}^{-1}$ at a depth of $30 \mathrm{~cm}$ beneath the surface. For the presently used plate sediment trap, the friction velocity $\left\langle u_{*}>\right.$, spatially averaged over the central collection area of $172 \mathrm{~cm}^{2}$, amounted to $0.51 \mathrm{~cm} \mathrm{~s}^{-1}$ at $u_{\mathrm{f}}=6.4 \mathrm{~cm} \mathrm{~s}^{-1}$. Increases in friction velocity generated for both types of plate traps sedimentation rates which are shown in Fig. 4. The plate trap sedimentation Eq. (4) is drawn as a regression line with the ensuing depositional threshold $u_{* \mathrm{~d}}$ placed at $0.6 \mathrm{~cm} \mathrm{~s}^{-1}$. Since the microcosm (plate trap type 4 ) was used to search for the depositional stress $\tau_{d}$ $\left(u_{* \mathrm{~d}}\right)$ of the heaviest particle subgroup, its results were not included in the preparation of the regression curve 


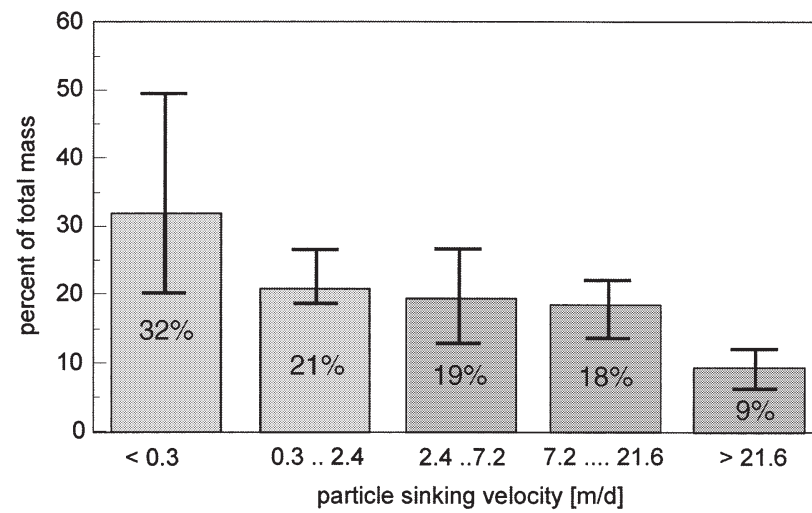

Fig. 3. Sinking velocity spectrum of suspended particles at Mühlenfliess in Fürstenwalde (Site 1) on July 20, 1998. Means of 3 measurements each. Error bars indicate minimum and maximum values per sinking-particle subgroup

for the plate trap data. For the $70 \mathrm{~mm}$ cylinder trap, the ratio between approaching flow speed at the aperture and internal cell flow speed $u_{\mathrm{D}}$ inside the trap was found to be 10 to $30 \%$, which agrees at flow speeds $>2$ $\mathrm{cm} \mathrm{s}^{-1}$ with the ratios reported in Table 3 of Gust et al. (1996) within given error margins.

\section{DISCUSSION}

With results from the water flow, the calibrated $70 \mathrm{~mm}$ cylinder, the $45 \mathrm{~mm}$ cylinder, the plate sediment traps, the settling velocities and concentrations of the sinking-particle pool, and the trap accumulation model, a set of tools was assembled which permitted experimental verification of the accumulation equation for cylinders, and identification of the connection between the in situ sinking-particle flux and cylinder trap collection rates.

\section{Comparisons of the collection rates}

The most conspicuous feature of the collection rates given in Table 4 is the significant difference between the cylindrical (types 1 and 2) and the plate sediment traps (types 3 and 4). The trapping rate ratios between these 2 groups varied between 5 and 27 (10 on average) and demonstrate that plate traps collected less material than cylinders at all approach velocities. This finding is in accordance with all other experiments made earlier and at very different sites in River Spree and Lake Müggel (Kozerski \& Leuschner in press) for trap types 1 and 3 , for which ratios between 1 and 30 were found. Within the group of the cylinders, the traps with $45 \mathrm{~mm}$ i.d. collected less material than

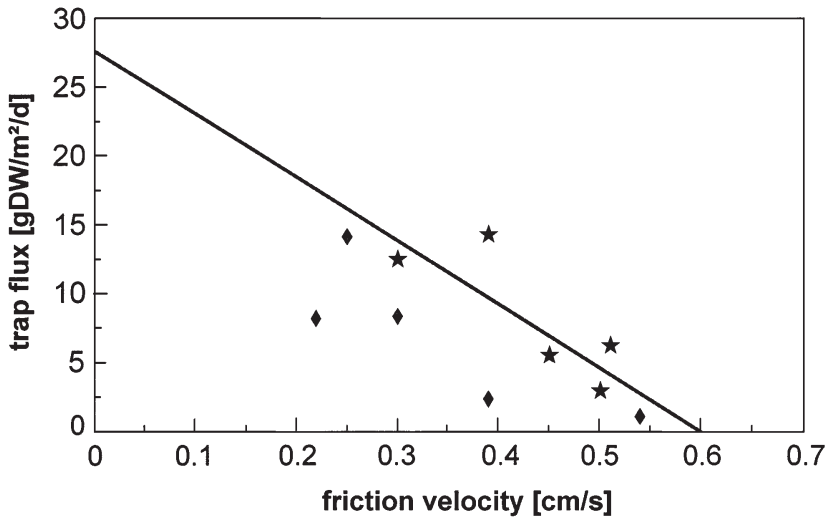

Fig. 4. Comparison of trap fluxes for plate sediment traps. ( $\star$ ) Plate sediment trap type 4 (named microcosm in Fig. 1); and $(\downarrow)$ plate sediment trap type 3 . For the plate trap (type 4 ), the $\left\langle u_{*}\right\rangle$ values were user-selected independent of the approaching flow speed. The values of $\left\langle u_{*}\right\rangle$ at 0.45 and $0.5 \mathrm{~cm} \mathrm{~s}^{-1}$ are estimates from the drag law, since no measurements were taken for these runs. Regression line determined for values of heaviest particle subclass $\left(W_{\mathrm{s}}=30 \mathrm{~m} \mathrm{~d}^{-1}\right)$ for plate sediment trap (type 3$)\left(\mathrm{r}^{2}=0.68\right)$

those with $70 \mathrm{~mm}$ i.d. as expected from their smaller aperture area. The observation of generally higher trapping rates $M_{\text {Tmeas }} / A t$ for the smaller traps (with full aperture $A$ used in the calculations) is addressed below. Gust et al. (1996) have shown that for monosized particle populations Eq. (3) should not be applied to convert collection data obtained under flow into trap fluxes; the same is found here for mixed populations.

Table 4. Mass per trap (in milligrams dry weight [mg DW]) accumulations and trap fluxes at Site 1 . The full trap aperture area $A$ is used to calculate the trap flux $\left(M_{\text {Tmeas }} / A t\right)$. Recent observations reveal that particles enter the trap through an active trap aperture $A_{\mathrm{s}}$ which represents only a fraction of the full aperture $A$ (see Gust et al. 1996). "Values are not valid due to leakage

\begin{tabular}{|c|c|c|c|c|c|}
\hline & 1 & 2 & $\begin{array}{c}\text { Run no. } \\
3\end{array}$ & 4 & 5 \\
\hline $\begin{array}{l}\text { Approach } \\
\text { velocity }\left(\mathrm{cm} \mathrm{s}^{-1}\right)\end{array}$ & 2.1 & 3.2 & 4.5 & 6.4 & 6.2 \\
\hline Duration (min) & 150 & 150 & 855 & 150 & 827 \\
\hline \multicolumn{6}{|c|}{ As mass per trap (mg DW) } \\
\hline Plate trap 1 & 22 & 25 & 51 & 10 & 25 \\
\hline Plate trap 2 & 17 & 13 & 46 & 7.5 & 25 \\
\hline Microcosm & 24 & 41 & 35 & 24 & 15 \\
\hline $45 \mathrm{~mm}$ cylinder & 9 & 14 & 59 & 13 & 62 \\
\hline 70 mm cylinder & 12 & $5.1^{*}$ & 98 & 19 & 81 \\
\hline \multicolumn{6}{|c|}{ As collection rates $\left(\mathrm{g} \mathrm{DW} \mathrm{m}^{-2} \mathrm{~d}^{-1}\right)$} \\
\hline Plate trap 1 & 12.1 & 13.8 & 5.0 & 5.6 & 2.5 \\
\hline Plate trap 2 & 9.6 & 7.0 & 4.5 & 4.2 & 2.6 \\
\hline Microcosm & 8.1 & 13.9 & 2.1 & 8.0 & 0.9 \\
\hline $45 \mathrm{~mm}$ cylinder & 54 & 82 & 62 & 80 & 68 \\
\hline $70 \mathrm{~mm}$ cylinder & 29 & $13^{*}$ & 43 & 48 & 37 \\
\hline
\end{tabular}


The collection rates of all traps are different in the 5 consecutive runs. This can be caused either by a changing quality of the suspended particles or, more realistically, by the diurnal pattern of their concentration which varied daily by $>30 \%$ between $c_{\min }$ and $c_{\max }$ during a prior survey (see Fig. 2). The gradual increase in daily mean temperature from 17.2 to $19^{\circ} \mathrm{C}$ was too small to anticipate measurable viscosity effects on the collection rates.

\section{Verification of the hydrodynamic collection models}

\section{Cylinders}

Verification of the mass accumulation equation (Eq. 1) was sought by the experiments for a natural mixture of particles with the sinking mass concentrated in the range of very low settling velocities (see Fig. 3). This can be done straightforwardly for the $70 \mathrm{~mm}$ trap for Runs no. 4 and 5 of Table 3 at $u_{\mathrm{f}}=6.4$ and $6.2 \mathrm{~cm} \mathrm{~s}^{-1}$, respectively. All input variables exist from laboratory calibrations and field measurements to compare the actually measured values $M_{\text {Tmeas }}$ with calculations of $M_{\mathrm{T}}$ via Eq. (1). For Run no. 4 (the $150 \mathrm{~min}$ measurement), the mean particle concentration $C_{0}$ at $12.0 \mathrm{mg} \mathrm{l}^{-1}$ had a fastest-settling particle fraction (set at $W_{\mathrm{s} 1}=30 \mathrm{~m} \mathrm{~d}^{-1}$ ) with a concentration of $c_{01}=1.09 \mathrm{mg} \mathrm{l}^{-1}$, a second-fastest particle fraction at $w_{\mathrm{s} 2}=14.4 \mathrm{~m} \mathrm{~d}^{-1}$ with a $C_{02}$ of $2.18 \mathrm{mg} \mathrm{l}^{-1}$, and $c_{03}$ was $2.34 \mathrm{mg} \mathrm{l}^{-1}$ for $w_{\mathrm{s} 3}=4.8 \mathrm{~m} \mathrm{~d}^{-1}$. For overnight Run no. 5, which lasted for $827 \mathrm{~min}$, a reduction in overall concentration $c_{0}$ by $20 \%$ to $10 \mathrm{mg} \mathrm{l}^{-1}$ was selected based on the diurnal cycles measured prior to our experiments at the site. The concentrations of the individual sinking-particle classes were lowered accordingly.

The trap yield function $y\left(w_{\mathrm{S}}, 6\right)$ of Fig. 5, describing the retention of particles with different $w_{\mathrm{s}}$ in the $70 \mathrm{~mm}$ cylinder at $u_{\mathrm{f}}=6 \mathrm{~cm} \mathrm{~s}^{-1}$, was generated from the yield functions $y\left(w_{\mathrm{s}}, u_{\mathrm{f}}\right)$ given in Fig. 9 of Gust et al. (1996) for the 3 particle classes settling at 13,54 and $173 \mathrm{~m} \mathrm{~d}^{-1}$ by holding $u_{\mathrm{f}}$ fixed at $6 \mathrm{~cm} \mathrm{~s}^{-1}$. For particle classes with $W_{\mathrm{s}}<13 \mathrm{~m} \mathrm{~d}^{-1}$, no experimental yield data exist to date. The results of Gust et al. (1996) suggest, though, that yield factors $y\left(w_{\mathrm{s}}, u_{\mathrm{f}}\right)$ then approach a limit value of 0 . With the help of Fig. 5, yield values of 0.30, 0.04, 0.01, $0.0,0.0$ for $u_{\mathrm{f}} \approx 6 \mathrm{~cm} \mathrm{~s}^{-1}$ were generated for the 5 particle subgroups comprising the discrete sinking-particle velocity spectrum with mean $w_{\text {si }}$ of $30,14.4,4.8,1.3$ and $0.2 \mathrm{~m} \mathrm{~d}^{-1}$ at the Mühlenfliess site.

Eq. (1) provides a detailed breakdown of the total collected mass into the contributing individual particle groups for cylindrical traps. For the $70 \mathrm{~mm}$ cylinder, Table 5 shows the calculated total collected mass as a result of the individual particle subgroup contributions from advective transport and gravitational settling for the different approach velocities $u_{\mathrm{f}}$ at Site 1 , and for 1 run from Site 2 (see below). The total mass accrued consists predominantly of advectively entering particles of the 3 fastest-sinking classes. To this a small gravitational contribution of the fastest-sinking particle class is added. The trapping ratio $R_{i}\left(=C_{0} Q / C_{0} A_{\mathrm{s}} W_{\mathrm{s}}\right)_{i}$, which enables differentiation between the advective and the gravitational collection contribution per particle subgroup, turns out to be 11.2 for the fastest-sinking particle group for flow speeds $u_{\mathrm{f}} \approx 6 \mathrm{~cm} \mathrm{~s}^{-1}$. This is close to the limit where separation between advective and gravitational trap flux is experimentally possible (see Fig. 14 of Gust et al. 1996). Furthermore the accumulation calculations show that the advectively originated mass contributions of the third-slowest particle group are of the same order of magnitude as the gravitational contribution of the fastest-sinking particle group. The particle accumulation calculations of $M_{\mathrm{T}}$ at $u_{\mathrm{f}} \approx 6 \mathrm{~cm} \mathrm{~s}^{-1}$ differ from the measured values $M_{\text {Tmeas }}$ by less than $(-) 30 \%$, which is an encouraging result in view of unavoidable error margins given. The test of consistency was extended to measuring Site 2 (River Spree at Werder). Here, for Run no. 1 on April 20, 1999, the calculated accumulation values at an approach velocity $6.2 \mathrm{~cm} \mathrm{~s}^{-1}$ differed by (+)30\% from the actually measured value for the $70 \mathrm{~mm}$ cylinder (Table 5). At present, we cannot explain the plus/minus variations of $M_{\text {Tmeas }}$ and $M_{\text {Tcalc }}$ at Sites 1 and 2 as either systematic error or random error from measurements/calibrations, or indication of seasonal differences. The data sample is too small.

These results lead us to test the accumulation model of the $70 \mathrm{~mm}$ cylinder at approach velocities $u_{\mathrm{f}}=2.1$ and $4.5 \mathrm{~cm} \mathrm{~s}^{-1}$ at Site 1 as well. In these cases, Eq. (1) was used with flushing rates $Q\left(u_{\mathrm{f}}\right)$ of 60 and $210 \mathrm{ml}$ $\mathrm{min}^{-1}$ (from Gust et al. 1996). The yield factors for the 2 fastest-sinking velocity classes were extrapolated from

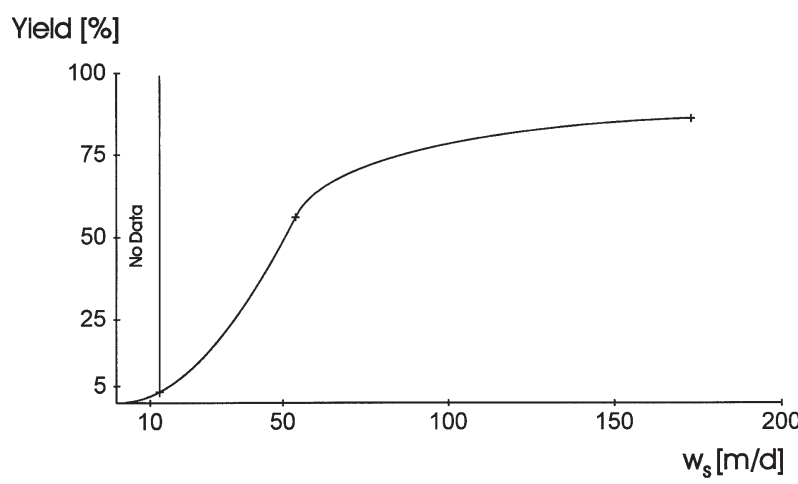

Fig. 5. Yield function $y=y\left(w_{\mathrm{s}}, 6\right)$ of the $70 \mathrm{~mm}$ cylinder trap (the MultiPIT) at $6.0 \mathrm{~cm} \mathrm{~s}^{-1}$ approach velocity. Note that for $W_{\mathrm{s}}$ $<13 \mathrm{~m} \mathrm{~d}^{-1}$ no yield data exist to date. $(+)$ represent data points for $\mathrm{ws}=13,54,174 \mathrm{~m} \mathrm{~d}^{-1}$, respectively 
Table 5. Test of the mass accumulation Eq. (1) for the $70 \mathrm{~mm}$ cylinder trap $\left(A=38.0 \mathrm{~cm}^{2}, A_{\mathrm{s}}=15.2 \mathrm{~cm}^{2}\right)$. The measured total mass $\left(M_{\text {Tmeas }}\right)$ is compared with the mass calculated by Eq. (1) $\left(M_{\text {Tcalc }}\right)$ based on known trap parameters and concentration values for the particle subgroups identified. The masses $M_{\mathrm{T} i}$ per particle subgroup are the sum of advective $\left(y_{i} C_{0 i} t Q\right)$ and gravitational $\left(y_{i} C_{0 i} t A_{\mathrm{s}} W_{\mathrm{si}}\right)$ contributions, and $M_{\mathrm{Tcalc}}=\sum M_{\mathrm{T} i}$. All calculated numbers are shown to the $1 \mu \mathrm{g}$ level only to demonstrate the procedure without addressing the issue of experimental uncertainty. Note that the trap calibrations of Gust et al. (1996) took place at $31^{\circ} \mathrm{C}$; present temperatures at Site 1 ranged from 17.2 to $19^{\circ} \mathrm{C}$, at Site 2 from 8.3 to $9.4^{\circ} \mathrm{C}$

\begin{tabular}{|c|c|c|c|c|c|c|c|c|c|c|c|c|}
\hline $\begin{array}{l}\text { Approach } \\
\text { velocity, } \\
u_{\mathrm{f}}\left(\mathrm{cm} \mathrm{s}^{-1}\right)\end{array}$ & $\begin{array}{r}\text { Particle } \\
\text { spe } \\
\left(\mathrm{m} \mathrm{d}^{-1}\right)\end{array}$ & $\begin{array}{l}\text { ettling } \\
\text {, } w_{\mathrm{s}} \\
\left.\mathrm{m} \mathrm{min}^{-1}\right)\end{array}$ & $\begin{array}{c}\text { Conc., } \\
C_{0 i} \\
\left(\mathrm{mg} \mathrm{l}^{-1}\right)\end{array}$ & $\begin{array}{c}\text { Flushing } \\
\text { rate, } Q \\
\left(\mathrm{ml} \mathrm{min}^{-1}\right)\end{array}$ & $\begin{array}{c}M_{\text {Tmeas }} \\
(\mu \mathrm{g})\end{array}$ & $\begin{array}{c}\text { Time, } t \\
(\min )\end{array}$ & Yield, $y$ & $\begin{array}{c}y_{i} C_{0 i} t Q \\
(\mu \mathrm{g})\end{array}$ & $\begin{array}{c}y_{i} C_{0 i} t A_{\mathrm{s}} W_{\mathrm{s} i} \\
(\mu \mathrm{g})\end{array}$ & $\begin{array}{l}M_{\mathrm{T} i} \\
(\mu \mathrm{g})\end{array}$ & $\begin{array}{c}M_{\text {Tcalc }} \\
(\mu \mathrm{g})\end{array}$ & $\begin{array}{c}M_{\text {Tmeas }} / \\
M_{\text {Tcalc }}\end{array}$ \\
\hline \multicolumn{13}{|l|}{ Site 1} \\
\hline 6.4 & $\begin{array}{l}30 \\
14.4 \\
3.8\end{array}$ & $\begin{array}{l}2.08 \\
1.0 \\
0.33\end{array}$ & $\begin{array}{l}1.09 \\
2.18 \\
2.34\end{array}$ & $\begin{array}{l}340 \\
340 \\
340\end{array}$ & 19300 & 150 & $\begin{array}{l}0.3 \\
0.04 \\
0.01\end{array}$ & $\begin{array}{r}16677 \\
4447 \\
1193\end{array}$ & $\begin{array}{r}1566 \\
199 \\
18\end{array}$ & $\begin{array}{r}18243 \\
4646 \\
1211\end{array}$ & 24100 & 0.8 \\
\hline 6.2 & $\begin{array}{l}30 \\
14.4 \\
4.8\end{array}$ & $\begin{array}{l}2.08 \\
1.0 \\
0.33\end{array}$ & $\begin{array}{l}0.9 \\
1.8 \\
1.95\end{array}$ & $\begin{array}{l}320 \\
320 \\
320\end{array}$ & 81400 & 827 & $\begin{array}{l}0.3 \\
0.04 \\
0.01\end{array}$ & $\begin{array}{r}71452 \\
19054 \\
5160\end{array}$ & $\begin{array}{r}7060 \\
905 \\
81\end{array}$ & $\begin{array}{r}78512 \\
19959 \\
5241\end{array}$ & 103712 & 0.78 \\
\hline 4.5 & $\begin{array}{l}30 \\
14.4 \\
4.8\end{array}$ & $\begin{array}{l}2.08 \\
1.0 \\
0.33\end{array}$ & $\begin{array}{l}0.9 \\
1.8 \\
1.95\end{array}$ & $\begin{array}{l}210 \\
210 \\
210\end{array}$ & 97800 & $\begin{array}{l}855 \\
855 \\
855\end{array}$ & $\begin{array}{l}0.55 \\
0.06 \\
0.015\end{array}$ & $\begin{array}{r}88877 \\
19391 \\
5252\end{array}$ & $\begin{array}{r}13380 \\
1404 \\
125\end{array}$ & $\begin{array}{r}10257 \\
20795 \\
5377\end{array}$ & 128429 & 0.76 \\
\hline 2.1 & $\begin{array}{l}30 \\
14.4 \\
4.8\end{array}$ & $\begin{array}{l}2.08 \\
1.0 \\
0.33\end{array}$ & $\begin{array}{l}1.09 \\
2.18 \\
2.34\end{array}$ & $\begin{array}{l}75 \\
75 \\
75\end{array}$ & 11520 & $\begin{array}{l}150 \\
150 \\
150\end{array}$ & $\begin{array}{l}0.7 \\
0.1 \\
0.02\end{array}$ & $\begin{array}{r}8584 \\
2453 \\
526\end{array}$ & $\begin{array}{r}3618 \\
497 \\
35\end{array}$ & $\begin{array}{r}12202 \\
2950 \\
561\end{array}$ & 15713 & 0.73 \\
\hline \multicolumn{13}{|l|}{ Site 2} \\
\hline 6.2 & $\begin{array}{l}54 \\
32 \\
14.4\end{array}$ & $\begin{array}{l}3.75 \\
2.2 \\
1.0\end{array}$ & $\begin{array}{l}0.16 \\
0.27 \\
0.42\end{array}$ & $\begin{array}{l}320 \\
320 \\
320\end{array}$ & 23800 & 254 & $\begin{array}{l}0.56 \\
0.33 \\
0.04\end{array}$ & $\begin{array}{l}7383 \\
7330 \\
1375\end{array}$ & $\begin{array}{r}1315 \\
766 \\
66\end{array}$ & $\begin{array}{l}8699 \\
8097 \\
1441\end{array}$ & 18237 & 1.30 \\
\hline
\end{tabular}

the original yield function data of Gust et al. (1996) (with reduced reliability, though) as 0.7 and 0.1 (for $u_{\mathrm{f}}=$ $2.1 \mathrm{~cm} \mathrm{~s}^{-1}$ ), and as 0.55 and 0.06 (for $u_{\mathrm{f}}=4.5 \mathrm{~cm} \mathrm{~s}^{-1}$ ). In both cases, the calculations of the accumulation rates deviated less than $30 \%$ from the actually measured values (Table 5). The yield factors applied still need a rigorous test, and the agreement between $M_{\text {Tmeas }}$ and $M_{\text {Tcalc }}$ should be viewed at present merely as a supportive trend.

The overall positive results for the $70 \mathrm{~mm}$ cylinder, reproducing closely the accumulated trap masses by the model framework, encouraged its extension to cylinders of different geometries. We selected the concurrently used $45 \mathrm{~mm}$ cylinder with $15.9 \mathrm{~cm}^{2}$ total aperture area $\left(\approx 6.5 \mathrm{~cm}^{2}\right.$ active aperture area $\left.A_{\mathrm{s}}\right)$. First estimates of the values of the trap-specific yield function $y_{45}\left(W_{\mathrm{si}}, u_{\mathrm{f}}\right)$, the flushing rate $Q_{45}\left(u_{\mathrm{f}}\right)$, and the active trap aperture $A_{\mathrm{s} 45}$ for particle entry were obtained in a subsequent field experiment in the River Spree near the hamlet of Werder in April 1999 (Site 2). With the sinking-particle spectrum and particle subgroup concentrations $C_{0 i}$ obtained from experiments with the aforementioned multiple-tube settling chamber, and the flushing rate measured for the $45 \mathrm{~mm}$ cylinder at $0.25 \mathrm{lmin}^{-1}$ at a mean approach velocity of $6.2 \mathrm{~cm} \mathrm{~s}^{-1}$, the yield factors of the $45 \mathrm{~mm}$ cylinder were determined via Eq. (1) to be $0.25,0.03,0.01$ for the 3 heaviest trap-retained particle subgroups with mean settling velocities $W_{\mathrm{s}}$ at $30,14.4,4.8 \mathrm{~m} \mathrm{~d}^{-1}$, respectively. With these values of $Q$ and $y$, the advective, gravitational and total collection rates of the $45 \mathrm{~mm}$ cylinder trap of the Spree experiments at Site 1 were estimated for Runs no. 4 and 5 (Table 6). The calculated total collected masses $M_{\mathrm{T} 45}$ amount to 14.7 and $64.6 \mathrm{mg} \mathrm{DW}$ for Runs no. 4 and 5, respectively, while the measured accumulation rates were 13.2 and $62.3 \mathrm{mg}$ DW (Table 6). This constitutes a satisfactory agreement.

Particle rejection thresholds of cylinders

At the measuring Site 1, only a $30 \%$ fraction of the total sinking-particle mass contributed to the mass collected by the trap. Of the sinking-particle mass (with very slow particle sinking speed) $70 \%$ moved with the circulation cell through the trap without measurable retention. For these particle groups, the yield factor must have become too small (see Fig. 5). Comparison of the distribution pattern of model particles (quartz beads) fed into a $70 \mathrm{~mm}$ cylinder with those collected at different approach velocities at its bottom (Fig. 11 of Gust et al. 1996) suggests that all particles settling at $\leq 5 \mathrm{~m} \mathrm{~d}^{-1}$ (equivalent to $10 \mu \mathrm{m}$ glass beads) are rejected for approach velocities $>12 \mathrm{~cm} \mathrm{~s}^{-1}$. This indication leads to the hypothesis that differences between trap calibration techniques occur when the subgroups comprising the in situ sinking-particle pool are reacting differently to chemical (example: attachment of radio- 
Table 6. Results for the $45 \mathrm{~mm}$ cylinder with aperture $A=16.3 \mathrm{~cm}^{2}$, and active aperture $A_{\mathrm{s}}=6.5 \mathrm{~cm}^{2}$. The measured total mass $\left(M_{\text {Tmeas }}\right)$ is compared with the mass calculated by Eq. (1) $\left(M_{\text {Tcalc }}\right)$ based on known trap and concentration values for the particle subgroups identified. The masses $M_{\mathrm{Ti}}$ per particle subgroup are the sum of advective and gravitational contributions, and $M_{\text {Tcalc }}$ $=\sum M_{\mathrm{Ti}}$. All calculated numbers are shown to the $1 \mu \mathrm{g}$ level only to demonstrate the procedure without addressing the issue of experimental uncertainty. Note that trap calibrations of Gust et al. (1996) took place at $31^{\circ} \mathrm{C}_{i}$ present temperatures at Site 1 ranged from 17.2 to $19^{\circ} \mathrm{C}$, at Site 2 from 8.3 to $9.4^{\circ} \mathrm{C}$

\begin{tabular}{|c|c|c|c|c|c|c|c|c|c|c|c|c|}
\hline $\begin{array}{l}\text { Approach } \\
\text { velocity, } \\
u_{\mathrm{f}}\left(\mathrm{cm} \mathrm{s}^{-1}\right)\end{array}$ & $\begin{array}{r}\text { Particle } \\
\text { spe } \\
\left(\mathrm{m} \mathrm{d}^{-1}\right)\end{array}$ & $\begin{array}{l}\text { settling } \\
\mathrm{d}, w_{\mathrm{s}} \\
\left(\mathrm{cm} \min ^{-1}\right)\end{array}$ & $\begin{array}{c}\text { Conc., } \\
C_{0 i} \\
\left(\mathrm{mg} \mathrm{l}^{-1}\right)\end{array}$ & $\begin{array}{c}\text { Flushing } \\
\text { rate, } Q \\
\left(\mathrm{ml} \mathrm{min}^{-1}\right)\end{array}$ & $\begin{array}{c}M_{\text {Tmeas }} \\
(\mu \mathrm{g})\end{array}$ & $\begin{array}{l}\text { Time, } t \\
(\min )\end{array}$ & Yield, $y$ & $\begin{array}{c}y_{i} C_{0 i} t Q \\
(\mu g)\end{array}$ & $\begin{array}{c}y_{i} C_{0 i} t A_{\mathrm{s}} W_{\mathrm{s} i} \\
(\mu \mathrm{g})\end{array}$ & $\begin{array}{l}M_{\mathrm{T} i} \\
(\mu g)\end{array}$ & $\begin{array}{c}M_{\text {Tcalc }} \\
(\mu \mathrm{g})\end{array}$ & $\begin{array}{c}M_{\text {Tmeas }} / \\
M_{\text {Tcalc }}\end{array}$ \\
\hline 6.4 & $\begin{array}{l}30 \\
14.4 \\
4.8\end{array}$ & $\begin{array}{l}2.08 \\
1.0 \\
0.33\end{array}$ & $\begin{array}{l}1.09 \\
2.18 \\
0.34\end{array}$ & $\begin{array}{l}260 \\
260 \\
260\end{array}$ & 13160 & 150 & $\begin{array}{l}0.25 \\
0.03 \\
0.01\end{array}$ & $\begin{array}{r}10628 \\
2551 \\
913\end{array}$ & $\begin{array}{r}553 \\
64 \\
8\end{array}$ & $\begin{array}{r}11181 \\
2615 \\
921\end{array}$ & 14717 & 0.90 \\
\hline 6.2 & $\begin{array}{l}30 \\
14.4 \\
4.8\end{array}$ & $\begin{array}{l}2.08 \\
1.0 \\
0.33\end{array}$ & $\begin{array}{l}0.9 \\
1.8 \\
1.95\end{array}$ & $\begin{array}{l}250 \\
250 \\
250\end{array}$ & 62300 & 827 & $\begin{array}{l}0.25 \\
0.03 \\
0.01\end{array}$ & $\begin{array}{r}46519 \\
11165 \\
4032\end{array}$ & $\begin{array}{r}2516 \\
290 \\
35\end{array}$ & $\begin{array}{c}49035 \\
11455 \\
4067\end{array}$ & 64557 & 0.96 \\
\hline
\end{tabular}

nuclides such as TH234 or TH230) or mechanical (example: by $w_{\mathrm{s}}$ ) tagging. Furthermore it is no contradiction to state that cylindrical traps will automatically undertrap all indicators for ecosystem processes which are coupled to the rejected, slow-settling particle fractions. The problem is inseparably linked to the magnitude of the approaching flow in relation to particle settling or deposition threshold speeds and exists for all trap geometries including cylinders, cones and flat plates. The overcollection of faster-settling particles (through advective contributions) cannot compensate for, or be coupled to, the winnowing or loss of slowersinking particle mass by traps. Since the yield function $y\left(w_{\mathrm{s}}, u_{\mathrm{f}}\right)$ of a cylinder trap does not maintain a constant value, the particle size and mass distribution of a mixed-particle population sampled under flow is inevitably different from that in the open water column. The role of slow-sinking particles can be studied, though, by using free-floating traps (Buesseler et al. 2000, Valdes \& Price 2000).

\section{Plate sediment trap}

At this stage, the measured collection rates of the plate sediment trap came into focus. This trap had been calibrated independently in a laboratory flume and tested in the same river channel by means of spores. The results demonstrated the equivalence of mass sedimentation rates on the trap surface with observed losses in a mass balance experiment over a river segment (Kozerski \& Leuschner 2000). This is an established calibration protocol for the gravitationally settling flux (Gardner 1980). The goal in this study was to test if the flat-plate sedimentation rates (as independent means) lead to consistent results with the gravitational component of cylinder trap accumulation rates as predicted by the model Eq. (1).
For the plate sediment trap, no internal flushing loop exists. Particle entry and extraction zones are linked to the flat-plate surface, and collection rates relate to the plate hydrodynamics. Particle extraction occurs at the surface of the plate, with the acting local bottom stress $\tau$ (often expressed as friction velocity $u_{*}$ ) generated by the approach velocity $u_{\mathrm{f}}$. With all independent variables known from the experiments, the validity of Eq. (4) was tested with data from Site 1 for the heaviest subgroup of the sinking particles. The flow-generated friction velocity $\left\langle u_{*}\right\rangle$ varied in Runs no. 1 to 5 from 0.3 to $0.51 \mathrm{~cm} \mathrm{~s}^{-1}$ on the surface of the plate sediment trap, while the critical depositional friction velocity was estimated as $\mathrm{u}_{* \mathrm{~d}} \approx 0.6 \mathrm{~cm} \mathrm{~s}^{-1}$ for the fastest-sinking particles from the experiments with the microcosm (plate trap type 4).

Calculations of collection rates from mass retained on the plate by Eq. (4) show the correct trend (Fig. 4): decreasing sedimentation rates are found for increasing plate surface stress and decreasing mean concentration $c_{0}$. Extrapolation to the no-flow condition, where the ratio $u_{*} / u_{* \mathrm{~d}}$ approaches the value of 0 , provides an estimate of the in situ flux rate of $27.6 \mathrm{~g} \mathrm{DW}$ $\mathrm{m}^{-2} \mathrm{~d}^{-1}$ for the fastest-settling particle class. For the range of approach velocities experienced, the collection rates of the plate sediment trap thus indeed provide a confirming test for the calculated gravitational component of the cylinder-trap collected mass for the fastest-sinking particle settling velocity class. This contribution $M_{\text {Tgrav1 }}=\left(y c_{\mathrm{o}} w_{\mathrm{s}} A_{\mathrm{s}} t\right)_{1}$ translates into an in situ flux value of 27.0 (night) and 33.0 (day) g DW m ${ }^{-2} \mathrm{~d}^{-1}$ for the $70 \mathrm{~mm}$ cylinder.

Based on the observed measuring uncertainties of the variables $u_{*}, c_{0}, u_{* \mathrm{~d}}$, and $w_{\mathrm{s}}$, an uncertainty factor of 2 is obtained for $M_{\mathrm{TP}}$ from the error propagation law. The validity of Eq. (4) as approximation of the settling flux of boundary-layer traps under flow requires further experiments in the laboratory with known mono- 
sized particle classes under precisely controlled hydrodynamic and sedimentological conditions.

In situ sinking-particle flux approximation of Gust et al. (1996)

Under flow, the total mass $M_{\text {Tmeas }}$ collected in a cylinder rarely provides immediate information about the sinking-particle flux. To obtain sinking-particle fluxes, subsequent calculations need to provide the product of concentrations $C_{0 i}$ and settling velocities $W_{\mathrm{si}}$ of the sinking-particle subgroups (running index $i$ ).

Gust et al. (1996) proposed that by rearranging the trap accumulation Eq. (1) the in situ flux of particles collected by a cylinder trap can be obtained. For a sinking-particle spectrum comprised of multiple particle groups, in situ fluxes and total trap flux are linked by Eq. (2), which reads in detail

$$
\begin{aligned}
& W_{\mathrm{s} 1} C_{01}+W_{\mathrm{s} 2} C_{02}+W_{\mathrm{s} 3} C_{03}+\ldots= \\
& {\left[M_{\mathrm{T} 1} /\left(y_{1} A_{\mathrm{s}} t\right)-Q C_{01} / A_{\mathrm{s}}\right]+\left[M_{\mathrm{T} 2} /\left(y_{2} A_{\mathrm{s}} t\right)-Q C_{02} / A_{\mathrm{s}}\right]} \\
& +\left[M_{\mathrm{T} 3} /\left(y_{3} A_{\mathrm{s}} t\right)-Q C_{03} / A_{\mathrm{s}}\right]+\ldots
\end{aligned}
$$

The flux Eq. (5) shows that for mixed-particle populations the contributions of the individual sinking-particle classes to the total trap flux (itemized in Table 5 for the $70 \mathrm{~mm}$ cylinder and in Table 6 for the $45 \mathrm{~mm}$ cylinder for 3 particle subgroups) are not yet amenable to an experimental protocol, since all partial masses $M_{\mathrm{T} i}$ are lumped into the total collected mass $M_{\text {Tmeas }}$. As a consequence, with the deployment of a single trap type (for example, only $70 \mathrm{~mm}$ cylinders) in a sinkingparticle pool comprised of several subgroups distinguished by $W_{\text {si }}$ the flux correction Eq. (2) can only provide an inequality for the fastest-sinking particle group with the total collected mass $M_{\text {Tmeas }}$ replacing the (unknown) heaviest subgroup mass $M_{\mathrm{T} 1}$ :

$$
W_{\mathrm{s} 1} C_{01} \geq M_{\text {Tmeas }} /\left(y_{1} A_{\mathrm{s}} t\right)-Q C_{01} / A_{\mathrm{s}}
$$

The equal sign in Eq. (6) holds for a monosized sinking-particle population (since here $M_{\text {Tmeas }}=M_{\mathrm{T} 1}$ ). In the latter case the in situ flux is obtained once $c_{01}$ and $y_{1}$ are known. While in our field experiments the in situ flux $W_{\mathrm{s} 1} C_{01}$ amounted to $27-31 \mathrm{~g} \mathrm{DW} \mathrm{m}^{-2} \mathrm{~d}^{-1}$, obtained from the settling chamber method and $27-33 \mathrm{~g} \mathrm{DW} \mathrm{m}^{-2} \mathrm{~d}^{-1}$ from the accumulation Eq (1), the advective contributions of the simultaneously trapped 2 slower-sinking particle classes to $M_{\text {Tmeas }}$ lead to an upper flux limit of $M_{\text {Tmeas }} /\left(y_{1} A_{\mathrm{s}} t\right)-Q c_{01} / A_{\mathrm{s}}=55 \mathrm{~g} \mathrm{DW} \mathrm{m}^{-2} \mathrm{~d}^{-1}$. As a consequence, until $M_{\text {Tmeas }}$ can be separated into subgroups $M_{\mathrm{Ti}}$, the approach via Eq. (2) cannot provide in situ fluxes from mixed-particle collection rates. On the other hand, by using the SCM concurrently with the cylinders, and taking Eq. (1) to calculate individual gravitational mass contributions $\left(M_{\text {Tgrav }}\right)_{i}$ from $M_{\text {Tmeas }}$ and subsequently Eq. (2) to calculate the in situ flux, consistency for the heaviest subgroup of the in situ sinking particles was found between the 2 independent techniques (Table 7).

$$
\begin{aligned}
& \text { Insight from the verification efforts } \\
& \text { of the accumulation Eq. (1) }
\end{aligned}
$$

The examples and calculations show that the accumulation model of Gust et al. (1996) explains well the measured collection rates of particle mass in cylindrical traps. In particular, the experiments revealed:

(1) Mixed-particle populations were the standard in the field;

(2) For traps exposed to flow, the mass accumulation Eq. (1) enables differentiation between advective and gravitational particle contributions. Eq. (1) has been verified through independent approaches for the 70 and $45 \mathrm{~mm}$ cylinders such as:

(2.1) comparison of actually collected particle masses and those predicted by Eq. (1);

(2.2) comparison of the gravitational component of the heaviest particle subgroup of the accumulated mass of the $70 \mathrm{~mm}$ cylinder, calculated from Eq. (1), with independent measurements from the settling chamber, the plate sediment trap, and a cylinder of different geometry;

(3) The different particle masses collected in the larger and smaller cylinder lead to the same value of the in situ flux for the heaviest-particle subgroup (as they should) upon application of Eq. (1), while this is not possible via Eq. (3);

(4) Under flow, the trap flux Eq. (3) needs to be replaced by Eq. (1) for cylinders. As a consequence, shown by Eq. (2), a single type of (cylinder) trap exposed to flow in a single experiment cannot provide in situ fluxes of sinking-particle mixtures. In the limit of $u_{\mathrm{f}} \rightarrow 0$, Eq. (1) merges into Eq. (3).

\section{A cylinder trapping protocol for non-zero slip velocities}

The tasks of sinking-particle interceptors (sediment traps) encompass both the collection and preservation of accumulated material for further investigations and the determination of the in situ sinking-particle flux. If a device (such as the settling chamber array used here, or others) can provide both the settling velocities $W_{\mathrm{si}}$ and the concentrations $C_{0 i}$ of the sinking-particle subgroups, then the sinking-particle flux $\sum\left(C_{0} W_{\mathrm{s}}\right)_{i}$ is known and traps would only be needed to sample the oceans. For oceanic applications, such an experimental approach has not been realized to date. The mass accumulation equation 
for cylindrical traps opens the path to a protocol for trap deployments under flow which links cylinder trap collection rates and the in situ sinking-particle flux.

\section{Deriving in situ sinking-particle flux from cylinder trap data}

\section{Conceptual/theoretical aspects}

The mass accumulation equation (Eq. 1) involves 2 groups of variables in the description of the collection process. The first group relates to trap variables, whose flow dependence can be determined by laboratory or field calibrations. The second group relates to the particle variables $w_{\mathrm{si}}$ and $c_{0 i}$, which for flux investigations constitute the unknowns. Once the first-group variables have been determined by calibrations for a cylinder, they subsequently appear as coefficients in Eq. (1). This has been demonstrated above in the mass accumulation intercomparisons for the 70 and $45 \mathrm{~mm}$ cylinders. The remaining dependent variables are the sinking-particle subgroup concentrations $C_{0 i r}$ of which typically more than 1 contributes to $M_{\text {Tmeas }}$ per trap (see Table $5 \& 6$ ), and the settling velocities $w_{\mathrm{si}}$. Combining the accumulation equations (Eq. 1) of the 70 and $45 \mathrm{~mm}$ cylinders shows that they form a solvable system of equations for 2 sinking-particle subgroup concentrations $C_{01}, c_{02}$ when data about $W_{\mathrm{s} 1}$ and $W_{\mathrm{s} 2}$ are available. That step is realized experimentally by deploying the 2 trap types simultaneously close to each other in the same flow and particle environment. By generalization, simultaneous deployment of as many cylinder types as sinking-particle subgroups contribute to the trap-retained mass links the collected mass $\left(M_{\text {Tmeas }}\right)_{n}$ per trap $n$ ( $n=$ running index for traps) with the in situ concentrations of the trap-collected particle subgroups $i$. To solve this system of equations, its rank needs to coincide with the number of sinkingparticle subgroups which contributed (measurably) to the collected mass $M_{\text {Tmeas }}$ in each of the traps. The structure of this system of equations is presented in Table 8 for cylinders, to which the plate sedimentation equation has been added for a possible trap type alternative. A condition for the solution of the system of equations is their linear independence. This requires the coefficients formed by the yield function, flushing rate, and active aperture to be different for the cylindrical trap types chosen ( $n$ traps of the same geometry are insufficient), and for the plate trap to collect the same particle subgroups.

If, as in our case, 3 particle groups contribute measurably to $M_{\text {Tmeas }}$ per trap, then 3 independent equations are needed. This requirement is met when 3 different types of traps with individual (independent) collection
Table 7. Comparison of in situ fluxes of heaviest-particle subgroup(s) obtained by independent methods for velocities $u_{\mathrm{f}} \approx$ $6 \mathrm{~cm} \mathrm{~s}^{-1}$. SCM: settling chamber method, GPA: from total accumulated mass of cylinders via Eqs. (1) \& (2) using experimental values $c_{0 i}$. All values in $\mathrm{g} \mathrm{DW} \mathrm{m} \mathrm{m}^{-2} \mathrm{~d}^{-1}$

\begin{tabular}{|c|c|c|c|c|}
\hline & Run no. & $w_{\mathrm{s} i}\left(\mathrm{~m} \mathrm{~d}^{-1}\right)$ & SCM & GPA \\
\hline $4.5 \mathrm{~cm}$ cylinder & & & & \\
\hline $\begin{array}{l}\text { Site 1, Day } \\
\text { Night }\end{array}$ & $\begin{array}{l}4 \\
5\end{array}$ & $\begin{array}{l}30 \\
30\end{array}$ & $\begin{array}{l}31.4 \\
27.0\end{array}$ & $\begin{array}{l}32.7 \\
27.1\end{array}$ \\
\hline $7.0 \mathrm{~cm}$ cylinder & & & & \\
\hline $\begin{array}{l}\text { Site 1, Day } \\
\text { Night }\end{array}$ & $\begin{array}{l}4 \\
5\end{array}$ & $\begin{array}{l}30 \\
30\end{array}$ & $\begin{array}{l}31.4 \\
27.0\end{array}$ & $\begin{array}{l}33.0 \\
27.0\end{array}$ \\
\hline $\begin{array}{l}\text { Site } 2 \text {, } \\
\text { Particle subgroup } 1 \\
\text { Particle subgroup } 2\end{array}$ & $\begin{array}{l}1 \\
1\end{array}$ & $\begin{array}{l}54 \\
32\end{array}$ & $\begin{array}{l}8.6 \\
9.5\end{array}$ & $\begin{array}{l}9.2 \\
9.0\end{array}$ \\
\hline
\end{tabular}

features are used. For example, 3 cylinders with different diameters and adequate aspect ratios could be chosen. It could likewise be envisioned that combinations of cylinders and a plate trap are selected. In either case, the number of particle subgroups contributing (measurably) to the accumulated mass has to be the same for the traps selected. Particle subgroup concentrations $C_{01}$, $C_{02}, C_{03}$ are obtained by solving the 3 -trap equation system. Note that for determining the values of $C_{0 i}$, the settling velocity $W_{s i}$ per particle subgroup has to be known or obtained during the field deployment of the multiple-trap array. The product of the variables leads to the desired sinking-particle fluxes $\left(C_{0} W_{\mathrm{s}}\right)_{i}$.

The interdependencies between trap diameter, active trap aperture, yield function, flushing rate (the trap variables), mean settling speed (the particle varibles) and mass accrued per trap (the result) are known presently in limited ranges for the 70 and $45 \mathrm{~mm}$ cylinders, and are lacking for other diameters to date. The solution of the equation system of Table 8 will be sensitive to the error margins of the measured trap-, particle-, and site-specific variables. With the growth of this data pool the presently existing experimental uncertainty levels will be reduced.

\section{Ensuing trap array design}

For the example of Table 8, the simultaneous deployment of 3 cylinder traps was selected with diameters of 45, 70, and $100 \mathrm{~mm}$, respectively. Other diameters could be chosen as well, requiring new trap calibration efforts, though. The traps can be mounted on a single trap frame such that the rotary multiplecup collection manifold utilizes existing technology. As to the determination of settling velocities $W_{\mathrm{si}}$ video and attenuation meter techniques have advanced to a 
Table 8. System of equations to determine concentrations $C_{0 i}$ of sinking-particle subgroups from steady-state mass accumulations in a trap array with 3 trap types (example assumes 3 subgroups). To obtain in situ fluxes $\left(c_{0} W_{\mathrm{s}}\right)_{i}$, multiply results by $W_{\mathrm{s} i}$ from concurrent measurements of settling speeds. Roman numerals mark traps with different geometry (dimensions). Traps I-III: cylinders, trap IV: plate trap. Particle variables are $c_{0 i}, w_{\mathrm{si}}, \tau_{\mathrm{d} i}$. When environmental and coupled trap variables $u_{\mathrm{f}}, Q\left(u_{\mathrm{f}}\right)$ and $y\left(w_{\mathrm{s}}, u_{\mathrm{f}}\right)$ vary with time during a collection period (due to tides, for example), approximate or numerical solution techniques may be required. The fourth equation, determining plate-trap collection behavior, can be used in lieu of either of the cylinders in case the relation between $u_{\mathrm{d} i}$ and $\tau$ permits deposition for the same particle subgroups

$$
\begin{aligned}
M_{\text {TmeasI }} & =c_{01}\left[y_{\mathrm{II}} t\left(Q_{\mathrm{I}}+A_{\mathrm{I}} W_{\mathrm{s} 1}\right)\right]+c_{02}\left[y_{\mathrm{II}} t\left(Q_{\mathrm{I}}+A_{\mathrm{I}} W_{\mathrm{s} 2}\right)\right]+c_{03}\left[y_{\mathrm{II}} t\left(Q_{\mathrm{I}}+A_{\mathrm{I}} W_{\mathrm{s} 3}\right)\right] \\
M_{\text {TmeasII }} & =c_{01}\left[y_{\mathrm{II} 1} t\left(Q_{\mathrm{II}}+A_{\mathrm{II}} W_{\mathrm{s} 1}\right)\right]+c_{02}\left[y_{\mathrm{II} 2} t\left(Q_{\mathrm{II}}+A_{\mathrm{II}} W_{\mathrm{s} 2}\right)\right]+c_{03}\left[y_{\mathrm{II} 3} t\left(Q_{\mathrm{III}}+A_{\mathrm{III}} W_{\mathrm{s} 3}\right)\right] \\
M_{\text {TmeasIII }} & =c_{01}\left[y_{\mathrm{III} 1} t\left(Q_{\mathrm{IIII}}+A_{\mathrm{III}} W_{\mathrm{s} 1}\right)\right]+c_{02}\left[y_{\mathrm{III} 2} t\left(Q_{\mathrm{III}}+A_{\mathrm{III}} W_{\mathrm{s} 2}\right)\right]+c_{03}\left[y_{\mathrm{III} 3} t\left(Q_{\mathrm{III}}+A_{\mathrm{III}} W_{\mathrm{s} 3}\right)\right] \\
M_{\text {TmeasIV }} & =c_{01}\left[w_{\mathrm{s} 1}-w_{\mathrm{s} 1}\left(\tau_{\mathrm{IV}} / \tau_{\mathrm{d} 1}\right)\right]+c_{02}\left[w_{\mathrm{s} 2}-w_{\mathrm{s} 2}\left(\tau_{\mathrm{IV}} / \tau_{\mathrm{d} 2}\right)\right]+c_{03}\left[w_{\mathrm{s} 3}-w_{\mathrm{s} 3}\left(\tau_{\mathrm{IV}} / \tau_{\mathrm{d} 3}\right)\right]
\end{aligned}
$$

level that in situ monitoring of $W_{\mathrm{s} i}$ is possible in the quiescent fluid volume inside traps for aggregates $>100 \mu \mathrm{m}$ (Thomsen et al. 1996), representing settling speeds $W_{\mathrm{si}} \geq 16 \mathrm{~m} \mathrm{~d}^{-1}$. Tests have to determine if 1 video camera per trap array rather than per trap type suffices to determine the $W_{\mathrm{si}}$ of the sinking-particle subgroups collected. Other avenues to obtain $W_{\mathrm{s} i}$ could be explored as well. The trap multiplett will carry an environmental flow sensor with adequate resolution to record the local flow field at trap aperture. Its hardware realization should permit synchronization with the monitoring channel of $w_{\mathrm{s} i}$ to allow differentiation between instationary high-flow and high-concentration flux events during the individual mass-collection intervals.

\section{Applications and refinements \\ Flux of slow-sinking particles}

Extending collection rates into the range of low particle sinking speeds $<13 \mathrm{~m} \mathrm{~d}^{-1}$, where in limnic environments a sizeable fraction ( 70 to $90 \%$ ) of the sinking-particle mass is concentrated, requires a reduction of the slip velocity between fluid and trap to increase the yield. This step can probably be achieved by switching from bottom-moored and surface-tethered trap arrays (Eulerian-frame experiments) to freedrifting platforms where the traps are carried along with the moving fluid (Lagrangian-frame experiments). In the latter case, the hydrodynamics affecting the mass collection may depend on a very low residual slip velocity at the trap aperture, the local turbulence structure and the eigenmotion of the platform in response to environmental stimuli such as internal waves, eddies, or fronts. No data have been collected to date to test if Eq. (1) remains valid for very weak internal circulation cells in the cylinder. Such cells have been shown to exist for a MultiPIT even at $u_{\mathrm{f}}=1$ $\mathrm{cm} \mathrm{s}^{-1}$ by Gust et al. (1996).

\section{Calibration of cylinder traps}

For traps obeying the accumulation Eq. (1), a practical way exists for calibrations in the field. The unknown yield function $y\left(w_{\mathrm{s}}, u_{\mathrm{f}}\right)$ can be obtained for different sinking-particle subgroups per fixed approach velocity from a system of equations as shown in Table 9. Here the dependent and independent trap and particle variables have been reassigned and the equation system represents a different experiment from that representing the equation system of Table 8. A single trap type under calibration is exposed to as many field experiments at same flow speed but different, independently determined sinking-particle concentrations $C_{0 i}$ (and, consequently, independent values of $M_{\text {Tmeas }}$ ) as particle subgroups contribute to the collected mass. The unknown flushing rate $Q$ is obtained from the lost volume of dyed fluid from the trap interior over known short-term time intervals. By the approach shown in Table 9 the hitherto unknown yield values $y_{45}\left(W_{\text {sir }} 6\right)$ and flushing rates $Q_{45}\left(u_{\mathrm{f}}\right)$ were obtained for the $45 \mathrm{~mm}$ cylinder trap at $u_{\mathrm{f}} \approx 6 \mathrm{~cm} \mathrm{~s}^{-1}$, which led to the results shown in Table 6 . The equation system can also be established by using accumulation data from different sites and seasons for the selected trap type as long as the sinking-particle subgroups and the approach velocities [that is, the variables determining $\left.y=y\left(w_{\mathrm{s}}, u_{\mathrm{f}}\right)\right]$ coincide.

\section{Correction/refinement of existing data}

Large data sets on trap fluxes exist where incomplete sets of the above identified necessary flow, trap, and particle parameters have been recorded during collection. 
Table 9. System of equations to determine the yield factor $y=y\left(w_{\mathrm{s}}, u_{\mathrm{f}}\right)$ of cylinder trap T1 from collected masses $M_{\mathrm{T} 1 i}$ at same approach velocity (and thus $Q_{1}$ ) yet different concentrations of same sinking-particle subgroups during deployments. Example is shown for 3 particle subgroups with known concentrations $C_{0 \text { nir }}$ where $i=$ running index for particle subgroup, $n=$ running index for number of experiment by same trap type

$$
\begin{aligned}
& M_{\mathrm{T} 11}=y_{1} C_{011} t_{1}\left(Q_{1}+A_{\mathrm{s}} W_{\mathrm{s} 1}\right)+y_{2} C_{012} t_{1}\left(Q_{1}+A_{\mathrm{s}} W_{\mathrm{s} 2}\right)+y_{3} C_{013} t_{1}\left(Q_{1}+A_{\mathrm{s}} W_{\mathrm{s} 3}\right) \\
& M_{\mathrm{T} 12}=y_{1} C_{021} t_{2}\left(Q_{1}+A_{\mathrm{s}} W_{\mathrm{s} 1}\right)+y_{2} C_{022} t_{2}\left(Q_{1}+A_{\mathrm{s}} W_{\mathrm{s} 2}\right)+y_{3} C_{023} t_{2}\left(Q_{1}+A_{\mathrm{s}} W_{\mathrm{s} 3}\right) \\
& M_{\mathrm{T} 13}=y_{1} C_{031} t_{3}\left(Q_{1}+A_{\mathrm{s}} W_{\mathrm{s} 1}\right)+y_{2} C_{032} t_{3}\left(Q_{1}+A_{\mathrm{s}} W_{\mathrm{s} 2}\right)+y_{3} C_{033} t_{3}\left(Q_{1}+A_{\mathrm{s}} W_{\mathrm{s} 3}\right)
\end{aligned}
$$

Refined information on in situ mass fluxes should be extractable from such existing trap samples by renewed experiments at selected original sites which use the original trap type and an additional calibrated cylinder multiplett. When for similar field conditions, which need to include the local flow field, season/event and collection duration, the new collections of the original trap match the old flux and flow data, then the accompanying calibrated trap array can provide the actual sinking-particle flux (from solving its equation system [Table 8] and recording $w_{\text {si }}$ ) and establish the link between trap flux and in situ flux. Alternatively, the originally used trap could be calibrated and incorporated into the multipletrap array. The extent to which conical traps can be included in this new concept of simultaneous deployment of several independent, calibrated trap types (not replications of 1 trap type) depends on the still missing evaluation of how far the particle accumulation process of this trap type can be described unambiguously by an equation of similar structure to Eq. (1).

\section{Next steps}

Determining the masses of the in situ sinking-particle flux is one aspect of the multitude of studies related to sinking organic and inorganic particles. Of more interest mostly is the biogeochemical, elemental and organismal composition of the vertical flux (Blomqvist \& Hakanson 1981). The way these are linked to the different sinking-particle subgroups needs to be established, though, by a proper protocol now that trap fluxes can be linked to the in situ mass flux. This poses a new level of complexity which should be approached in a next step: to separately collect the different particle subgroups within the collection cup, and to devise experimental strategies where identification of the concise mass flux (both mathematically and experimentally) is coupled with parent-daughter isotope studies and in situ automatic water sampling, for example. Furthermore, shallow deployment of a combination of flat-plate and cylindrical traps may offer an avenue to devise controlled feeding experiments (and thus lead to more insight into the swimmer problem).
Acknowledgements. We thank Dr Klaus Leuschner, Mirko Mania, Christian Feld, and Dirk Hopsch from the Institute of Freshwater Ecology and Inland Fisheries, Dr-Ing. Volker Mueller and Ulrich Arning from TUHH for field, laboratory, and calibration work, and WSA Berlin/Aussenbezirk Fürstenwalde for technical support. This study was supported in part by BMBF grant no. BEO 0339564.

\section{LITERATURE CITED}

Baker ET, Milburn HB, Tennant DA (1988) Field assessment of sediment trap efficiency under varying flow conditions. J Mar Res 46:573-592

Blomqvist S, Hakanson L (1981) A review on sediment traps in aquatic environments. Arch Hydrobiol 91:101-132

Buesseler KO (1991) Do upper-ocean sediment traps provide an accurate record of particle flux? Nature 353:420-423

Buesseler KO, Steinberg DK, Michaels AF, Johnson R J, Andrews JE, Valdes JR, Price JF (2000) A comparison of the quantity and composition of material caught in a neutrally buoyant versus surface-tethered sediment trap. Deep-Sea Res 47:277-294

Butman CA (1986) Sediment trap biases in turbulent flows: results from a laboratory flume study. J Mar Res 44: 645-693

Gardner WD (1980) Sediment trap dynamics and calibration: a laboratory evaluation. J Mar Res 38:17-39

Gust G (1987) Verfahren und Vorrichtung zum Erzeugen von definierten Bodenschubspannungen. Deutsches Patentamt, München. Patent Nr. 3717969:1-51

Gust G (1988) Skin friction probes for field applications. J Geophys Res 93:14121-14132

Gust G, Mueller V (1997) Interfacial hydrodynamics and entrainment functions of currently used erosion devices. In: Burt N, Parker R, Watts J (eds) Cohesive sediments, 4th Nearshore and Estuarine Cohesive Sediment Transport Conference INTERCOH '94, Wallingford, England. J Wiley and Sons, New York, p 149-174

Gust G, Byrne RH, Bernstein R, Betzer PR, Bowles W (1992) Particle fluxes and moving fluids: experience from synchronous trap collections in the Sargasso Sea. Deep-Sea Res 39:1071-1083

Gust G, Michaels AF, Johnson R, Deuser WG, Bowles W (1994) Mooring line motions and sediment trap hydromechanics: in situ intercomparison of three common deployment designs. Deep-Sea Res 42:831-857

Gust G, Bowles W, Giordano S, Hüttel M (1996) Particle accumulation in a cylindrical sediment trap under laminar and turbulent steady flow: an experimental approach. Aquat Sci 58:297-326

Hawley N (1988) Flow in cylindrical sediment traps. J Great Lakes Res 14:76-88 
Junglewitz A, Mueller V, Gust G (1997) Calibration of a hot film sensor for application in turbulent ship model testing, ASME Fluids Engineering Division Summer Meeting (FEDM97), paper 3468 (CD-Rom), Vancouver

Knauer GA, Martin JH, Bruland KW (1979) Fluxes of particulate carbon, nitrogen and phosphorus in the upper water column of the northeast Pacific. Deep-Sea Res 26:97-108

Kozerski HP (1994) Possibilities and limitations of sediment traps to measure sedimentation and resuspension. Hydrobiologia 284:93-100

Kozerski HP, Leuschner K (2000) A new plate sediment trap: design and first experiences. Verh Int Verein Limnol 27: $242-245$

Kozerski HP, Koehler J, Schellenberger G (1991) Transport of

Editorial responsibility: Otto Kinne (Editor),

Oldendorf/Luhe, Germany particulate nutrients and pollutants in the lowland river Spree. IAHS Publ 203:359-366

Michaels AF, Bates NR, Buesseler KO, Carlson CA, Knap AH (1994) Carbon-cycle imbalances in the Sargasso Sea. Nature 372:537-540

Thomsen L, Jähmlich S, Graf G, Friedrichs M, Wanner S, Springer B (1996) An instrument for aggregate studies in the benthic boundary layer. Mar Geol 135:153-157

Valdes JR, Price JF (2000) Neutrally buoyant upper ocean sediment trap. J Atmosph Ocean Technol 17:62-68

Westrich B (1988) Fluvialer Feststofftransport - Auswirkungen auf die Morphologie und Bedeutung für die Wassergüte. Schriftenreihe Wasser-Abwasser. 22. R. Oldenbourg Verlag, München

Submitted: October 7, 1999; Accepted: May 18, 2000

Proofs received from author(s): November 15, 2000 